\title{
Strates
}

STRATES Matériaux pour la recherche en sciences sociales

$8 \mid 1995$

La question de l'environnement: recherches parallèles en Espagne et en France

\section{Liste des articles parus dans les huit premiers numéros de Strates (1986-1995)}

\section{OpenEdition}

\section{Journals}

Édition électronique

URL : http://journals.openedition.org/strates/1104

DOI : $10.4000 /$ strates. 1104

ISSN : 1777-5442

Éditeur

Laboratoire Ladyss

Édition imprimée

Date de publication : 30 juin 1995

ISSN : 0768-8067

\section{Référence électronique}

"Liste des articles parus dans les huit premiers numéros de Strates (1986-1995) », Strates [En ligne], 8

| 1995, mis en ligne le 30 novembre 2005, consulté le 08 septembre 2020. URL : http:// journals.openedition.org/strates/1104; DOI : https://doi.org/10.4000/strates.1104

Ce document a été généré automatiquement le 8 septembre 2020

Tous droits réservés 


\section{Liste des articles parus dans les huit premiers numéros de Strates (1986-1995)}

1 (Les articles sont répertoriés par ordre alphabétique d'auteurs. Chaque article n'est répertorié qu'une seule fois, au nom du premier auteur.)

2 Archives de la Planète K (Anonyme), « La chasse de la famille K », 1986/1, p. 45-47.

3 BARRAQUÉ Bernard, « Région, régionalisme et aménagement », 1991/6, p. 143-160.

4 BATCHVAROV Marin, « La Bulgarie aujourd'hui : un cas dans les Balkans? », 1992-93/7, p. 13-24.

5 BECKOUCHE Pierre, «Compte-rendu d'une recherche sur l'électronique», 1986/1, p. 121-123.

6 - «Le redéploiement des groupes français de l'électronique change d'ampleur et de nature $", 1988 / 3$, p. 1-23.

7 - «Une région parisienne à deux vitesses L'accroissement des disparités spatiales dans l'Ile-de-France des années quatre-vingt », 1992-93/7, p. 85-103.

8 BERGER Martine, "La division sociale des espaces périurbains. Etat de la question ", 1986/1, p. 25-33.

9 - «Vers de nouveaux types de rapports villes-campagnes : la production des espaces périurbains en France et dans les pays développés d'économie libérale ", 1989/4, p. 89-106.

10 - «A propos des choix résidentiels des périurbains: peut-on parler de stratégies territoriales? », 1990/5, p. 125-128.

11 BERGER Martine \& RHEIN Catherine, «Parc de logements, structure des ménages et division sociale de l'espace en région Ile-de-France », 1988/3, p. 85-130.

12 BERGER Martine \& SAINT-GÉRAND Thierry, « La division sociale de l'espace périurbain en Ile-de-France. Application d'un système d'information statistique et cartographique », 1992-93/7, p. 43-57. 
13 - « Pour une approche de la main-d'œuvre agricole en Ile-de-France et dans le proche Bassin parisien », 1992-93/7, p. 59-66.

BLANCHARD de LA BROSSE Véronique, «L'espace, une dimension de la sociologie : la mobilité au féminin », 1990/5, p. 173-176.

BROCHOT Aline, «Territorialiser la politique de l'environnement en France. Quels outils pour l'évaluation et l'aide à la décision? », 1994-95/8, p. 59-80.

16 CARIOU Léontine, «Lire: la clé du monde. Récit d'une institutrice bigouden », 1992-93/7, p. 175-189.

17 CARROUÉ Laurent, «Division internationale du travail et structures régionales dans une industrie de haute technologie au sein de la CEE. Les industries informatiques, électriques et électroniques ", 1987/2, p. 35-62.

18 CHATELAIN Paul, "Quelques réflexions sur les rapports de la géographie à l'image ", 1989/4, p. 5-10.

19 CHAUVIRÉ Yvan, «L'inscription spatiale des comportements et des pratiques », 1990/5, p. 171-172.

CHAUVIRÉ Christiane et Yvan, Des frontières invisibles dans la ville? », 1990/5, p. 33-38.

21 CLAMMER John, "Le mythe de la race et de la Chine ancienne parmi les Chinois d'outre-mer. Mémoire, histoire, ethnicité », 1992-93/7, p. 25-41. COHEN Jeanine, « De la critique des sources statistiques », 1987/2, p. 21-27.

23 - «S'engager moins pour organiser mieux? Le paradoxe des stratégies territoriales d'entreprises », 1990/5, p. 49-57.

24 - «Ceci n'est pas un carnet de terrain. Villes de Tunisie 1964-1993 », 1992-93/7, p. 167-170.

DIAZ OJEDA Francisco José \& OJEDA RIVERA Juan Francisco, « Politiques de protection des espaces naturels. Le cas andalou », 1994-95/8, p. 81-91.

Equipe ESPACE, POPULATIONS ET SOCIÉTÉS, «Bibliographie: Division sociale de l'espace en Région Ile-de-France », 1987/2, p. 77-80.

27 Equipe GÉOGRAPHIE DU SYSTÈME PRODUCTIF, «Géographie du système productif français : une sélection bibliographique autour des travaux de l'équipe G.P.S. », 1987/2, p. 29-33.

FAGNANI Jeanne, «De l'utilisation du concept de stratégie en géographie sociale : quelques éléments de réflexion », 1990/5, p. 11-19. GLOBET Francine, «Configurations spatiales de données fiscales en Région Parisienne IRPP 1983 », 1987/2, p. 63-76. GOMEZ MENDOZA Josefina, MANUEL VALDES Carlos M. \& SAEZ POMBO Ester, « Gestion $\mathrm{du}$ territoire et de l'environnement dans un parc métropolitain : le Parc régional du haut bassin du Manzanares ", 1994-95/8, p. 104-113.

GOMEZ MENDOZA Josefina, MANUEL VALDES Carlos M., MATA OLMO Rafael \& SAEZ POMBO Ester, «Statut foncier, administration et gestion forestières durant la transition entre l'Ancien et le Nouveau régime : les montes de Madrid », 1994-95/8, p. 47-58. GONZALEZ FARACO Juan Carlos, « Doñana : tradition et changement social. Paradoxes d'un espace naturel charismatique », 1994-95/8, p. 2-38. 

p. 77-92. institutions concernées par l'aménagement rural en France depuis les années 1950 environ ", 1986/1, p. 125-140.

56 - « Au-delà des clichés... La photographie du paysage au service de l'analyse », 1989/4, p. 11-16.

57 - « Plus stratégique que le territoire, tu meurs... », 1990/5, p. 121-124. 
58

- «Politiques d'environnement: des chercheurs français et espagnols face à face», 1994-95/8, p. 5-16.

MARDUEL Marie-Laure, «Europe(s) rurale(s)? Premiers éléments d'une bibliographie », 1991/6, p. 131-142.

MATHIEU Nicole, «Eléments pour une bibliographie autour des termes : pays, petite région, développement local, développement micro-régional », 1986/1, p. 141-145.

- «Effets et dessous de la politique régionale: enquête en Limousin», 1988/3, p. 131-168.

- «Et qui reprendra la Bastille?», 1992-93/7, p. 163-166.

- «De l'importance et des difficultés de la mise en parallèle des politiques d'environnement ", 1994-95/8, p. 17-21.

MATHIEU Nicole \& PAIX Catherine, "Une charte en trois axes de recherche", 1992-93/7, p. 105-124.

MAUREL Marie-Claude, « Lectures pour penser l'Europe », 1991/6, p. 123-128.

MENDIBIL Didier, «Publicité et géographie : paysages, images et discours », 1989/4, p. 17-28.

MESINI Béatrice, « Une approche pluridisciplinaire : le revenu minimum d'insertion en milieu urbain », 1992-93/7, p. 141-150.

MESQUITA Zila, «Les nouvelles communes au Brésil : trois expériences d'émancipation dans une zone de modernisation agricole ", 1992-93/7, p. 125-139.

MOULIN Brigitte, "Avec quelles données statistiques travaillons-nous!», 1991/6, p. 161-172.

MOUSSET Sylvie, «Protection de la nature et gestion agricole dans le Parc National des Cévennes ", 1990/5, p. 181-190.

OJEDA RIVERA Juan F., CASTRO GARCIA Inmaculada, SOUBRANE Brindille \& VILLAR IGLESIAS Agustín, «Les espaces naturels, ces nouveaux territoires », 1994-95/8, p. 93-103.

PAIX Catherine \& PETIT Michèle, «Itinéraires et stratégies d'une bourgeoisie. Le cas de Singapour ", 1986/1, p. 49-119.

- «Un passé colonial et sa réinterprétation : la spécificité de la colonisation japonaise à Taïwan », 1987/2, p. 81-115.

74 - « La bourgeoisie à Singapour : une prosopographie », 1987/2, p. 117-128.

- «Une bibliographie sélective sur Taïwan », 1988/3, p. 31-39.

- «Espaces graphiques et pratiques de pouvoir : philosophies d'entreprises à Taïwan, préceptes politiques à Singapour », 1989/4, p. 29-65.

7 - «Géostratégies du capital et de l'État à Taïwan et Singapour », 1990/5, p. 59-70.

PANKO Walerian, «Les réformes communales en Pologne », 1991/6, p. 93-99.

PÉROUSE Jean-François, « Résidence et activités des étrangers dans un quartier rénové : l'exemple du quartier Combat dans le nord-est parisien », 1988/3, p. 41-62.

PETIT Michèle, « On est prié de reprendre son cœur au vestiaire », 1989/4, p. 125-127.

- «Rivages de l'Europe...» (Présentation de «La diaspora égéenne, récit d'une femme »), 1991/6, p. 173-176. 

l'analyse des sociétés rurales françaises dans Géopolitiques des régions françaises", 1987/2, p. 151-166.

85 - «Carnets de terrain », 1988/3, p. 169-179.

86 - «L'espace et le temps en Camargue, de Bernard Picon: une relecture», 1989/4, p. 163-165.

87 - «Stratégies territoriales: valeurs et usages dans les recherches rurales et agroalimentaires de STRATES », 1990/5, p. 105-112.

88 - « Attention à vos cartes !», 1992-93/7, p. 197-198.

89 PLET Françoise \& MATHIEU Nicole, « STRATES et l'Europe », 1991/6, p. 101-102.

90 PLIT Florian, « La dégradation de l'environnement en Pologne », 1991/6, p. 7-18.

91 POTRYKOWSKA Alina, «L'environnement en Pologne : état des lieux », 1991/6, p. 19-38.

92 POULOT-MOREAU Monique, «Planteurs et sucriers français. Les mutations exemplaires d'une filière classique », 1990/5, p. 177-180.

93

RHEIN Catherine, «Emploi et crise des grandes métropoles: Londres et New-York. Bibliographie sélective », 1986/1, p. 147-159.

94 - «Planification urbaine et régionale: leçons et perspectives des expériences étrangères », 1992-93/7, p. 67-84.

95 - « De la ville à l'urbanisation, de Gilles Montigny », 1992-93/7, p. 195-196.

96 RIVIERE Dominique, «Stratégies territoriales et aménagement du territoire. Le cas de l'aire de développement industriel Roma-Latina », 1990/5, p. 155-169.

97

ROBIC Marie-Claire, «Géographie - Politique - Régions françaises : trois questions à deux auteurs », 1987/2, p. 129-150.

98 - «Métropole/Métropôle. Les géographes et les métropoles d'équilibre », 1989/4, p. 67-88.

99

ROCHEFORT Michel \& ROUSSEL Monique, «Politique, stratégies et tactiques dans la dynamique d'un espace urbain : l'exemple de Brasilia », 1990/5, p. 97-102.

100 ROUSSEL Monique, «Les acteurs de la périurbanisation : stratégies et organisation de l'espace dans deux villages du sud de l'agglomération parisienne », 1988/3, p. 75-84.

101 SANTOS Milton, "Temps-Monde et Espace-Monde. Relever le défi conceptuel», 1992-93/7, p. 5-12.

SOWA Kazimierz Z., « Dégradation et restauration d'un patrimoine culturel : Cracovie », 1991/6, p. 53-64.

103 SZCZEPANSKI Marek S., "Catastrophe écologique, fragilité du mouvement vert: la voïvodie de Katowice », 1991/6, p. 39-52. 